\title{
PENGEMBANGAN MODUL PRAKTIKUM KIMIA ORGANIK 1 BERBASIS PROBLEM BASED LEARNING (PBL) DALAM MENINGKATKAN KETERAMPILAN SAINS
}

\section{PENGEMBANGAN MODUL PRAKTIKUM KIMIA ORGANIK 1 BERBASIS PROBLEM BASED LEARNING (PBL) DALAM MENINGKATKAN KETERAMPILAN SAINS}

\author{
Rahmawati*, Dwi Laksmiwati, Syarifa Wahidah Al Idrus, Aliefman Hakim dan Supriadi \\ Program Studi Pendidikan Kimia FKIP Universitas Mataram, Mataram, Indonesia \\ *Email: rahmawati_kimia@unram.ac.id
}

Diterima: 9 Februari 2021. Disetujui: 10 Februari 2021. Dipublikasikan: 3 Maret 2021

\begin{abstract}
Abstrak: Modul praktikum kimia organik 1 untuk pegangan mahasiswa praktikan pendidikan kimia semester 3 telah berhasil dikembangkan. Pengembangan modul telah melalui serangkaian proses validasi ahli, penjaringan respon dosen dan mahasiswa menggunakan instrumen angket, serta pengujian terbatas pada proses pembuatan video praktikum sebagai bahan praktikum virtual mata kuliah kimia organik 1. Pengembangan dilakukan dalam 4 tahapan yakni: tahap define (pendefinisian), tahap design (perancangan), tahap develop (pengembangan), dan tahap disseminate (penyebaran). Modul yang telah dikembangkan dinyatakan valid oleh validator dari segi kelayakan dengan nilai rata-rata sebesar 0.74 dan praktis dengan persentase sebesar $78.93 \%$. Responden memberikan respon sangat positif terhadap modul praktikum kimia organik 1 sehingga modul dinyatakan layak untuk dijadikan sebagai panduan melaksanakan praktikum karena dapat meningkatkan ketrampilan sains mahasiswa.
\end{abstract}

Kata kunci: Pengembangan, Modul, PBL, Kimia Organik 1

\begin{abstract}
The organic chemistry practicum module 1 for students to practice chemistry education in semester 3 has been successfully developed. Module development has gone through a series of expert validation processes, capturing the responses of lecturers and students using a questionnaire instrument, and limited testing on the process of making practicum videos as virtual practicum materials for organic chemistry courses 1 . The development is carried out in four stages, the define stage, the design stage, the develop stage and the dissemination stage. Modules that have been developed are declared valid by the validator in terms of feasibility an average value at 0.74 and practical percentage at $78.93 \%$. The respondents gave a very positive response to the organic chemistry practicum module 1 so that the module was deemed appropriate to be used as a guide for carrying out practicum because it could improve students' science skills.
\end{abstract}

Keywords: Development, Modul, PBL, Organic Chemistry 1

\section{PENDAHULUAN}

Pendidikan merupakan sebuah proses pengubahan sikap dan tata laku yang dialami oleh setiap individu dalam memperoleh pengetahuan, wawasan serta untuk mengembangkan sikap, keterampilan, dan potensi yang dimiliki [1]. Pendidikan dapat diperoleh dimana saja dan kapan saja, termasuk dalam praktikum.

Praktikum merupakan salah satu bentuk pembelajaran yang dilaksanakan pada tempat tertentu di mana mahasiswa dituntut untuk berperan secara aktif untuk menyelesaikan masalah yang diberikan melalui penggunaan alat, bahan serta metode yang sudah ditentukan. Dalam membantu proses berjalannya sebuah praktikum, mahasiswa menggunkan modul yang dibuat sebagai panduan agar praktikum berjalan dengan baik dan lancar [2]. Melalui kegiatan praktikum ini diharapkan motivasi belajar dan rasa ingin tahu serta keterampilan proses sains mahasiswa meningkat [3].

Melalui kegiatan praktikum ini diharapkan mahasiswa memperoleh pengalaman secara langsung sehingga dapat meningkatkan pemahaman konsep kimia, menumbuhkan minat dan motivasi, serta melatih kemampuan berpikir kritis dalam menyelesaikan praktikum kimia organik. Kegiatan praktikum di laboratorium merupakan bagian yang penting karena dapat melatih kemampuan ilmiah mahasiswa dalam mengobservasi fenomena alam yang ditemukan memudahkan mahasiswa melaksanakan pembalajaran praktikum [4].

Modul sangat diperlukan dalam kegiatan praktikum. Selain sebagai penuntun praktikum modul juga dapat digunakan sebagai media untuk mengarahkan mahasiswa agar mampu bekerja dengan langkah-langkah yang ilmiah sehingga dapat meningkatkan keterampilan generik sains mahasiswa karena keterampilan generik sains akan muncul pada pembelajaran yang berkaitan dengan teori-teori dan praktik [5-6].

Praktikum kimia organik ini memberikan mahasiswa kesempatan untuk lebih aktif mengembangkan kreativitasnya sendiri dalam 
menerapkan langkah-langkah atau metode kerja di laboratorium. Kegiatan praktikum pada mata kuliah kimia organik dimaksudkan agar mahasiswa dapat lebih aktif meningkatkan keterampilan berpikir, membangun pemahaman konsep, menumbuhkan keterampilan proses, menumbuhkan motivasi, dan melatih kemampuan psikomotorik.

Pada prodi pendidikan kimia, mata kuliah kimia organik diberikan selama 3 semester, yakni pada semester 3 dengan nama kimia 'organik 1' dan pada semester 4 dengan nama 'kimia organik 2'. Mata kuliah kimia organic adalah mata kuliah yang tentang senyawa yang terkandung dalam bahan hidup, tentang nama senyawanya, struktur molekul dan pengikatannya secara kimia, sifat fisik dan sifat kimianya, reaksi-reaksi pembuatannya, dan reaksi-reaksi kimia yang terjadi pada senyawasenyawa tersebut baik pada skala laboratorium maupun reaksi di alam.

Selama mengampu mata kuliah kimia organik beserta kegiatan praktikumnya, penulis menemukan fakta bahwa mahasiswa kesulitan untuk mengkorelasikan materi yang diterima di kelas dengan materi praktikum yang dilakukan sehingga kesatuan teori dengan praktik kegiatan pembelajaran seperti yang diharapkan oleh tuntutan SK silabus belum tercapai.

Salah satu alternatif strateginya adalah dengan mengembangkan media pembelajaran modul praktikum berbasis Problem Based Learning (PBL) yang menarik dan efektif melatih keterampilan mahasiswa untuk memperoleh pengetahuan dan pemahaman konsep yang bagus tentang materi kimia organik. PBL dapat diaplikasikan dalam materi koloid dikarenakan terdapat banyak masalah yang berkaitan dalam kehidupan sehari-hari yang dapat dijadikan sebagai permasalahan yang harus dipecahkan oleh mahasiswa baik secara mandiri maupun kelompok.

\section{METODE PENELITIAN}

Pengembangan dilakukan dalam 4 tahapan yakni: tahap define (pendefinisian), tahap design (perancangan), tahap develop (pengembangan), dan tahap disseminate (penyebaran).

Tahap define, langkah yang dilakukan berupa mendefinisikan dan membatasi apa saja yang menjadi ruang lingkup dan batasan dalam pengembangan modul praktikum ini, terdiri dari dua langkah, yakni analisis awal akhir dan analisis materi. Tahap perancangan (Design) bertujuan untuk merancang modul yang dikembangkan yaitu dengan melakukan pemilihan perancangan tampilan awal modul dan format isi modul. Pada tahap pengembangan, diminta pertimbangan secara teoritis dari ahli dan praktisi tentang kevalidan prototype 1 untuk memproleh prototype 2 (baru) dengan instrument penelitian berupa lembar validasi modul praktikum dan angket respon mahasiswa. Tahap develop ini menghasilkan prototype 3.

\section{HASIL DAN PEMBAHASN \\ Pengembangan Modul Praktikum}

Tahap awal dalam penelitian yaitu analisis awal akhir dan analisis materi. Analisis dilakukan terhadap beberapa literatur seperti jurnal, Rancangan Pembelajaran Semester (RPS), dan Rancangan Tugas Mahasiswa (RTM). Analisis terhadap Rancangan Pembelajaran Semester (RPS) yang terdiri dari kemampuan akhir yang diharapkan, bahan kajian serta indikator capaian, maka modul praktikum yang dikembangkan dapat digunakan dalam satu semester yaitu terdiri dari 3 sks teori dan 1 sks praktikum berisi 8 kali pertemuan praktik kimia organik di laboratorium.

Penyusun modul yang merupakan prototype 1 diawali dengan perancangan sampul modul, komponen modul, yaitu (1) kata pengantar, daftar isi, tata tertib praktikum, dan pengenalan laboratorium; (2) materi terkait dengan acara praktikum kimia organik 1; (3) proses praktikum yang berisi judul praktikum, tujuan praktikum, materi terkait praktikum, prosedur kerja, hasil pengamatan, pengolahan data, pertanyaan, dan pembahasan praktikum. Uji validitas menggunakan instrumen berupa lembar validasi ahli yang berisi komponen kegrafikan, komponen penyajian, komponen kelayakn isi, dan komponen kebahasaan. Analisis yang digunakan untuk meningkatkan kevalidan modul yaitu indeks Aiken dimana diperoleh dari tiga dosen validator yang memberikan nilai valid terhadap modul dan dapat digunakan setelah melakukan revisi. Selama proses penyusunan modul praktikum terdapat saran dari para validator yang perlu diperhatikan, diantaranya perbaikan dan penyesuaian untuk tulisan dan gambar pada modul praktikum, tata letak gambar, penambahan materi, penulisan pada modul, serta kalimat pada modul agar mudah dipahami. Sehingga didapatkan modul praktikum (prototype 2) yang sudah valid berdasarkan saran dan masukan dari validator.

Modul praktikum (prototype 2) diuji kepraktisannya kepada subjek (mahasiswa) semester 5 yang sudah mengambil mata kuliah kimia organik 1 program studi Pendidikan Kimia, FKIP Universitas Mataram. Uji kepraktisan yang dilakukan adalah uji skala terbatas pada 30 orang mahasiswa untuk memperoleh respon terhadap modul praktikum dengan cara memberikan angket respon. Angket terdiri dari 21 butir pernyataan, 10 pernyataan untuk komponen kemenarikan modul, 7 pernyataan untuk komponen kemudahan modul, dan 2 pernyataan untuk masing-masing komponen waktu pelaksanaan, dan komponen manfaat modul. Validasi dan uji kepraktisan menghasilkan modul praktikum prototype 3 . 


\section{Validitas Modul Praktikum}

Validasi dilakukan oleh tiga orang validatori yang berasal dari dosen Pendidikan Kimia FKIP Universitas Mataram.
Berdasarkan hasil validasi serta angket respon mahasiswa diperoleh modul praktikum kimia organik 1 yang telah valid dan praktis serta memenuhi kriteria untuk dapat digunakan sebagai panduan praktikum.

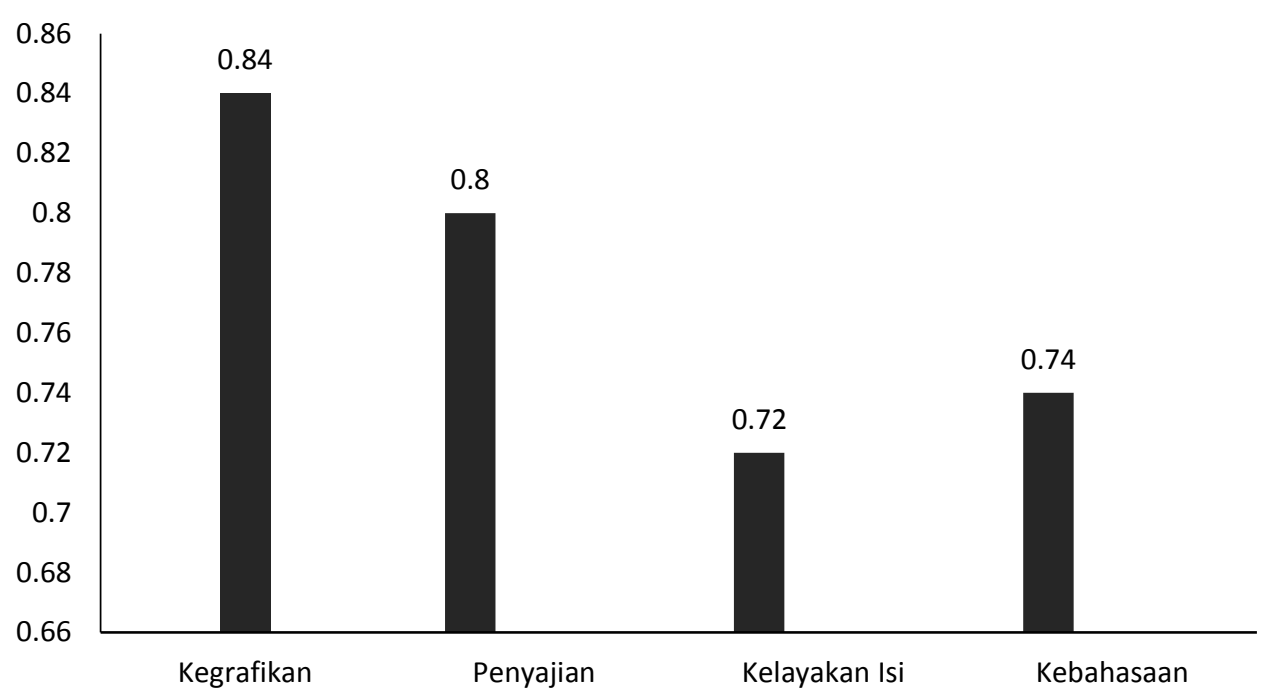

Gambar 1. Kelayakan Modul Praktikum

Berdasarkan gambar 1, hasil uji kelayakan modul praktikum yang telah dikembangkan berdasarkan empat aspek tersebut diperoleh ratarata 0.74 dengan kategori layak untuk diuji cobakan. Modul pengembangan ayng dinyatakan valid mampu mengukur peningkatan keterampilan sains mahasiswa dalam pembelajaran yang diterapkan. Modul yang valid dapat mengukur dan mengarahkan kegiatan proses pembelajaran mahasiswa secara tepat sesuai dengan proses ilmiah [7-9].

\section{Kepraktisan Modul Praktikum}

Tingkat kepraktisan dari modul praktikum yang dikembangkan diuji cobakan pada 20 orang mahasiswa Pendidikan Kimia yang telah mengambil mata kuliah kimia organik 1 . Aspek yang dinilai pada uji coba terbatas ini yaitu tampilan modul, kemudahan penggunaan modul, waktu pelaksanaan modul, dan manfaat modul. Berdasarkan indeks praktikalisasi diperoleh presentase rata-rata kepraktisan sebesar $78.93 \%$ dengan kategori praktis untuk digunakan dalam proses pembelajaran. Modul praktikum kimia berbasis problem based learning yang dikembangkan berdasarkan indeks praktikalitas diperoleh persentase rata-rata kepraktisan terhadap modul praktikum yang telah dikembangkan sebesar $82 \%$ dengan kategori sangat praktis untuk digunakan dalam proses pembelajaran [10-13].

Modul praktikum yang telah dinyatakan valid (dengan diuji validitas) dan praktis (uji kepraktiksan) telah digunakan sebagai panduan praktikum online (dalam bentuk video 2 acara praktikum) di masa pandemi oleh praktikum kimia organik 1 semester 3. Praktikum online tidak membuat mahasiswa menjadi tidak terampil dan tidak memiliki keterampilan sains. Namun, pengembangan terhadap peunjuk praktikum kimia organik 1 ini mendorong mahasiswa untuk melakukan kegiatan pengamatan dan memperoleh data untuk dibahas dalam laporan seperti praktikum pada umumnya.

\section{KESIMPULAN}

Berdasarkan uraian pada hasil dan pembahasan maka dapat disimpulkan bahwa modul praktikum kimia organik 1 yang dikembangkan masuk kategori layak untuk digunakan sebagai panduan dalam melaksanakan praktikum di laboratorium. Modul praktikum ini diharapkan mampu meningkatankan keterampilan sains mahasiswa pada mase pandemi. Keterampilan sains diperolehh melalui pengamatan dan analsis terhadap video praktikum kimia organik dalam pembelajaran.

\section{ACKNOWLEDGMENT}

Penelitian ini didanai dari DIPA BLU skema penelitian peningkatan kapasitas, nomor kontrak 2606/UN.18.L1/PP/2020.

\section{DAFTAR PUSTAKA}

[1] Sari, L. S., dan Sani, R. A., (2018). Analisa Keaktifan Siswa Dalam Pembelajaran Praktikum Fisika Di MAN 2 Model Medan, 
Jurnal Ikatan Alumni Fisika Universitas Negeri Medan, 4 (4), 11-15.

[2] Fajriyani. (2017). Pengembangan ModulPraktikum Kimia DasarTerintegrasi Ilmu Fisika Mahasiswa Jurusan Pendidikan Fisika, Skripsi, UIN Alauddin Makassar.

[3] Lubis, A. F., Lubis J. A., dan Lubis M. (2017). PEPRADASE (Pelatihan Praktikum Biologi Dengan Alat Dan Bahan Sederhana), Jurnal Pengabdian Masyarakat, 1 (1), 16-21.

[4] Muslim, M., Syuhendri, dan Saparini. (2017). Pengembangan modul Praktikum Elektronik Berbasis Proyek Untuk Meningkatkan Pemahaman Konsep Mahasiswa, Jurnal Inovasi Dan Pembelajaran Fisika, 150-156.

[5] Furqan, H., Yusrizal, dan Saminan. (2016). Pengembangan Modul Praktikum Berbasis Inkuiri untuk Meningkatkan Keterampilan Proses Sains dan Hasil Belajar Siswa Kelas X Di SMA Negeri 1 Bukit Bener Meriah, Jurnal Pendidikan Sains Indonesia, 4 (2): 124-129.

[6] Annisa, N. H., dan Sudarmin, S. (2016). Pengaruh Pembelajaran Guided Inquiry Berbantuan Diagram Vee Terhadap Keterampilan Generik Sains Siswa, Jurnal Inovasi Pendidikan Kimia, 10 (1).

[7] Ningsyih, S., Junaidi, E., \& Al Idrus, S. W. (2016). Pengaruh Pembelajaran Praktikum Berbasis Inkuiri Terbimbing Terhadap Kemampuan Berpikir Kritis Dan Hasil Belajar Kimia Siswa. Jurnal Pijar Mipa, 11(1).

[8] Yasmin, N., Ramdani, A., \& Azizah, A. (2015). Pengaruh metode inkuiri terbimbing terhadap keterampilan proses sains dan hasil belajar biologi siswa kelas VIII di SMPN 3 Gunungsari tahun ajaran 2013/2014. Jurnal pijar MIPA, 10(2).

[9] Sapitri, R. D., Hadisaputra, S., \& Junaidi, E. (2020). Pengaruh penerapan praktikum berbasis kearifan lokal terhadap keterampilan literasi sains dan hasil belajar. Jurnal Pijar Mipa, 15(2), 122-129.

[10]Laksmiwati, D., Hadisaputra, S., \& Siahaan, J. (2019). Pengembangan Modul Praktikum Kimia Berbasis Problem Based Learning Untuk Kelas XI SMA. Chemistry Education Practice, 1(2), 36-41.

[11] Islamiati, E. F., Anwar, Y. A. S., \& Hakim, A. (2020). Pengembangan Petunjuk Praktikum Kimia Bahan Alam Tentang Isolasi Sinamaldehid dari Kayu Manis. Chemistry Education Practice, 3(2), 104-111.

[12]Fajarianingtyas, D. A., \& Hidayat, J. N. (2020). Pengembangan petunjuk praktikum berorientasi pemecahan masalah sebagai sarana berlatih keterampilan proses dan hasil belajar mahasiswa IPA Universitas Wiraraja. Jurnal Pendidikan Sains Indonesia (Indonesian Journal of Science Education), 8(2), 152-163.

[13] Astuti, S., Danial, M., \& Anwar, M. (2018). Pengembangan LKPD Berbasis PBL (Problem Based Learning) Untuk Meningkatkan Keterampilan Berpikir Kritis Peserta Didik Pada Materi Kesetimbangan Kimia. Chemistry Education Review (CER), 90-114. 